\title{
Direct Electrochemistry of Hemoglobin on Graphene Nanosheet-based Modified Electrode and Its Electrocatalysis to Nitrite
}

\author{
Ping Liu, Xiuhua Zhang*, Lijun Feng, Huayu Xiong, Shengfu Wang
}

Ministry-of-Education Key Laboratory for the Synthesis and Application of Organic Functional Molecules \& College of Chemistry and Chemical Engineering, Hubei University, Wuhan 430062, China

*Corresponding Author:

Xiuhua Zhang

Tel.: +86-27-50865309

Fax: +86-27-88663043

E-mail: zhanganal@yahoo.com.cn

Received: 12 October 2010; | Revised: 7 December 2010; | Accepted: 20 December 2010

\begin{abstract}
A novel amperometric nitrite $\left(\mathrm{NO}_{2}^{-}\right)$sensor was developed based on immobilization of hemoglobin $(\mathrm{Hb})$ on a graphene nanosheet modified electrode by chitosan-N, N-Dimethylformamide (CS-DMF) hydrogel. The surface morphologies of the modified electrode were characterized by SEM, and direct electrochemistry of $\mathrm{Hb}$ on the graphene nanosheet-based electrode were investigated by cyclic voltammetry. The results indicated that $\mathrm{Hb}$ immobilized on the surface of the graphene modified electrode could keep its bioactivity, exhibited a surface-controlled electrochemical process and had a fast heterogeneous electron transfer rate with the rate constant $\left(k_{\mathrm{s}}\right)$ of $58.77 \mathrm{~s}^{-1}$. Moreover, the resulting biosensor showed excellent electrocatalytic activities toward nitrite reduction with a low detection limit of $1.8 \times 10^{-7} \mathrm{M}$ and a small apparent Michaelis-Menten constant $\left(k_{\mathrm{m}}\right)$ up to $12 \mu \mathrm{M}$. The good performance of the proposed sensor is attributed to excellent conductivity and electron mobility of graphene, and good biocompatibility of chitosan, which enhances the $\mathrm{Hb}$ content and promotes direct electron transfer between redox $\mathrm{Hb}$ and the surface of electrodes.
\end{abstract}

Keywords: Hemoglobin; Graphene; Nitrite; Electrocatalysis.

\section{Introduction}

Graphene (GR), a single atomic plane of graphite packed into a dense honeycomb crystal structure, was novel and fascinating carbon material since experimentally produced in 2004 [1]. The elusive two-dimensional structure of GR has numerous unexpected properties, such as

Am. J. Biomed. Sci. 2011, 3(1), 69-76; doi: 10.5099/aj110100070 excellent electrical conductivity, high surface area, and electron mobility at room temperature, robust mechanical properties and flexibility [2]. Another advantage of GR is its potential low manufacturing cost as compared to other nanostructured carbon materials, such as carbon nanotubes [3]. Due to its amazing properties, much research effort has been made to explore its fascinating applications in electroanalytical

(C) 2011 by NWPII. All rights reserved. 
chemistry or electrochemistry as novel electrode material for fabricating various biosensors. For instance, Wang et al. adopted the GR-modified electrode to selectively detect dopamine in a large excess of ascorbic acid [4]. Li et al. fabricated a GR and Nafion based electrochemical platform for ultrasensitive detecting of cadmium [5]. Niu and co-workers constructed a novel polyvinylpyrrolidone-protected GR/polyethyleneiminefunctionalized ionic liquid/glucose oxidase electrochemical biosensor [6]. Lin and co-workers immobilized glucose oxidase to the hybrid nanocomposite of GR-chitosan and succeeded in realizing direct electron transfer [7]. Zhao et al. utilized chitosan-dispersed GR nanoflakes to immobilize Cytochrome $\mathrm{c}$ and achieved direct electron transfer and determination of nitric oxide [8]. Chen and his team utilized chitosan and GR composite film for encapsulation of $\mathrm{Hb}$ to detect peroxide hydrogen [9]. Wang et al. fabricated a sensitive and mercury-free electrochemical sensing platform for analysis of the lead and cadmium by using GR (dispersed in Nafion-G solution) in combination with in situ plated bismuth film electrode [10].

Nitrite, which extensively exists in the environment and is widely used in food preservation, has been proved that its excess level in the blood leads to haemoglobin oxidation [11]. Once entering human body, nitrite would react with amines to form carcinogenic N-nitrosamines [12]. Due to these reasons, many methods have been developed for determination of nitrite, such as titrimetric [13], catalytic-spectrophotometric [14-16, 17], chromatographic [18, 19], and electrochemical techniques [20-22]. Among them, electrochemical methods show great advantage for quick response, low cost, high sensitivity, as well as abilities to be miniaturized. Modified electrodes with suitable catalyst can not only achieve the purpose with an improved reduction response of $\mathrm{NO}_{2}^{-}$, but also provide a means of extending the dynamic range in analytical determinations [23]. Zhu et al. have reported an electrochemical method for the determination of nitrite by using hemoglobin/room temperature ionic liquid/PDDAfunctionalized graphene composite film modified electrode [24]. Although the detection limit of $0.04 \mu \mathrm{M}$ was achieved, the fabrication processes of the modified electrode were obviously complex.

In this paper, hemoglobin $(\mathrm{Hb})$ was chosen as a model redox protein because of its commercial availability and a known and documented structure. Chitosan (CS) was employed as the building component of $\mathrm{Hb}-\mathrm{CS}-\mathrm{DMF}$ film not only because of its good biocompatibility and good film-forming ability, but also due to its positively charged property at physiological $\mathrm{pH}$ $\left(\mathrm{pH}<\mathrm{p} K_{\mathrm{a}}=6.3\right)$ [25], which would benefit $\mathrm{Hb}$ to adsorb on GR (negatively charged). The direct electrochemistry of $\mathrm{Hb}$ immobilized on the $\mathrm{Hb}$ CS-DMF/GR film was studied, and the potential application of the proposed electrode for the detection of nitrite was explored.

\section{Experimental}

\subsection{Reagents and materials}

Bovine hemoglobin $(\mathrm{Hb})$ and chitosan was purchased from Fluka (Switzerland). Graphene (GR) was kindly provided by Professor Xianbao Wang from Faculty of Materials Science and Engineering, Hubei University, China. The graphite oxide (GO) was prepared from graphite powders by following a method described by Hummers and Offeman [26]. This suspension of GO was ultrasonicated until it become clear with no particulate matter. The sonicated mixture was then treated with hydrazine hydrate, and the mixture was heated in an oil bath at about $100{ }^{\circ} \mathrm{C}$ in a water-cooled condenser for about $24 \mathrm{~h}$. As a result, the reduced GO gradually precipitated as a black solid. This black solid was then filtered and washed with a copious volume of deionized water and methanol. Following this, the precipitate was dried using continuous $\mathrm{N}_{2}$ flow for about $10 \mathrm{~h}$.

\subsection{Apparatus and procedures}

A computer-controlled electrochemical workstation (CHI 660C, CH Instruments, Chenhua Co., Shanghai, China) was carried out for cyclic voltammetry (CV) and amperometric measurement. A conventional three-electrode system was used in the measurements, with a bare GCE (3mm diameter) or a modified GCE as the working electrode, a saturated calomel electrode (SCE) as the reference electrode and a platinum 
electrode as the auxiliary electrode. The $\mathrm{pH}$ value of electrolyte was determined by using a 320-S acidity meter (Mettler-Toledo, Switzerland). A JEOL JSM-5510LV scanning electron microscopy (SEM, Japan) was applied for characterizing the prepared electrodes. All measurement was carried out at a room temperature. All experimental solutions were deaerated by nitrogen (kept over the solution during measurement).

\subsection{Preparation of the modified electrode}

All the modified electrodes were prepared by simple drop-casting technique. To get the best CV responses of $\mathrm{Hb}-\mathrm{CS}-\mathrm{DMF} / \mathrm{GR}$ films, experimental condition of film casting, such as the solvent for dispersing $\mathrm{GR}$, the concentration of $\mathrm{Hb}$, the ratio and the volume of the $\mathrm{Hb}-\mathrm{CS}-\mathrm{DMF}$ mixture, were optimized. Typically, GR (1.0 mg) was dispersed in $1.0 \mathrm{~mL} \mathrm{DMF}$, and then the mixture was agitated in an ultrasonic bath for $1 \mathrm{~h}$ to give a black suspension. The concentration of $\mathrm{Hb}$ stock solution, prepared by dissolving $\mathrm{Hb}$ in $0.05 \mathrm{M}$ phosphate buffer solution ( $\mathrm{PBS}, \mathrm{pH}=7.0$ ), was 20

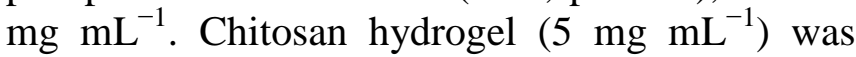
prepared by dissolving $10 \mathrm{mg}$ chitosan in $2.0 \mathrm{~mL}$ of $0.1 \mathrm{~mol} \mathrm{\textrm {L } ^ { - 1 }}$ acetic acid. Hb solution, CS hydrogel and DMF with a volume ratio of $5: 4: 1$ were mixed thoroughly to form a uniform mixture.

Prior to modification, the bare GCE was polished on chamois leather with $0.05 \mu \mathrm{m}$ alumina powder. Then it was thoroughly sonicated in deionized water and absolute ethanol, respectively. The cleaned GCE was coated by casting $5 \mu \mathrm{L}$ of the black GR suspension and dried in the air for $4 \mathrm{~h}$ to remove the solvent. Then the graphene modified electrode (GR/GCE) was obtained. Subsequently, $10 \mu \mathrm{L}$ of the mixture ( $\mathrm{Hb}, \mathrm{CS}$ and DMF with the volume ratio of 5:4:1) was spread evenly onto the surface of the resulting GR/GCE to achieve the Hb-CS-DMF/GR/GCE. For comparison, $\mathrm{Hb}-\mathrm{CS} / \mathrm{GR} / \mathrm{GCE}$, CSDMF/GR/GCE and Hb-CS-DMF/GCE were prepared with the similar procedures as described above.

\section{Results and discussion}

\subsection{Morphology studies by scanning electron microscopy}

A set of representative SEM morphologies of GR and other hybrid films deposited on glassy carbon surface are shown in Fig.1. The image of GR (Fig.1a) shows clearly large sheet-like shape with slightly scrolled edges. Most GR nanosheets were lying flat, and some GR nanosheets fold together. From Fig. 1b, it can be seen that $\mathrm{Hb}$ were embedded in chitosan film that revealed approximately flat and featureless. This compact structure would not benefit electron transfer. In contrast, after the addition of DMF, Hb-CSDMF/GR film (Fig.1c) exhibited a threedimensional network porous structure, which could serve as a good path way for electron transfer. It's said DMF can accelerate gelation of chitosan films, and the formation of porous arranged at the film surface might attribute to the synergistic result of lots of nonspecific and other interactions such as hydrophobic interactions, hydrogen bonding and dispersion forces among the chitosan, DMF and $\mathrm{Hb}$, as our previous report [27].
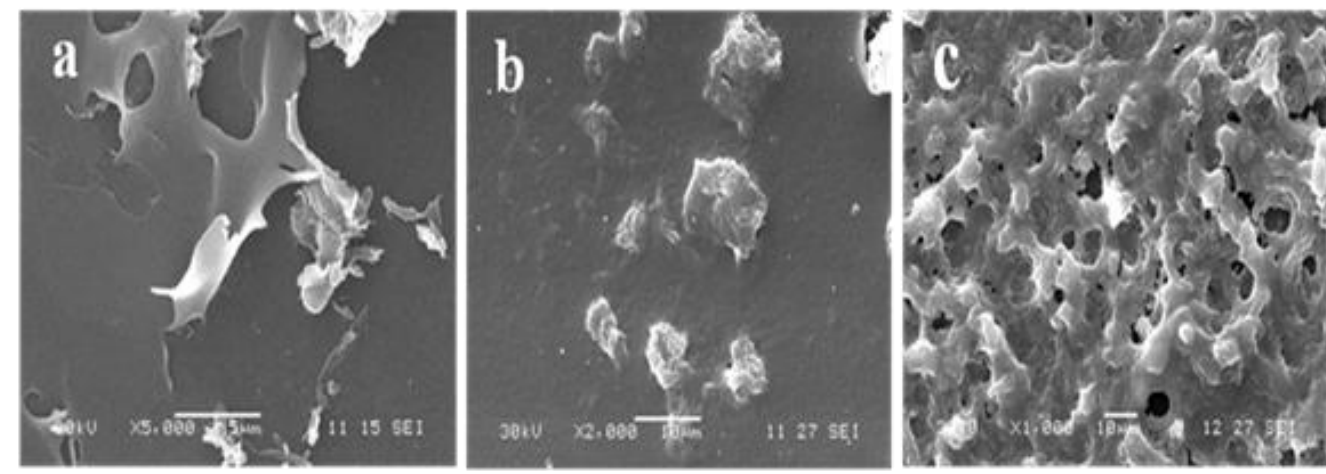

Fig. 1 SEM images of GR (a), Hb-CS/GR film (b) and Hb-CS-DMF/GR film (c) on the glassy carbon. 


\subsection{Direct electrochemistry of $\mathrm{Hb}$ on $\mathrm{Hb}$-CS- DMF/GR/GCE}

Fig.2 shows the typical CVs of different modified electrodes in $\mathrm{pH} 7.0$ PBS. No voltammetric peak was observed at CSDMF/GR/GCE (Fig.2b) in potential window, which illustrates that the peaks of Hb-CSDMF/GCE (Fig.2a), Hb-CS/GR/GCE (Fig.2c) and Hb-CS-DMF/GR/GCE (Fig.2d) were attributed to the presence of $\mathrm{Hb}$. $\mathrm{Hb}-\mathrm{CS}-\mathrm{DMF} / \mathrm{GR} / \mathrm{GCE}$ (Fig.2d) gave a couple of stable, well-defined and nearly reversible redox peaks at $-0.257 \mathrm{~V}$ and $-0.399 \mathrm{~V}$. The formal potential $\left(E^{0}\right)$ is $-0.328 \mathrm{~V}$ vs. SCE, which is located at the potential characteristic of the heme $\mathrm{Fe}^{\mathrm{III}} / \mathrm{Fe}^{\mathrm{II}}$ redox couple of proteins [28]. For Hb-CS-DMF/GCE (Fig.2a), a couple of redox peaks of $\mathrm{Hb}$ is unconspicuous, especially the peak of oxidation, and the background current is lower than that of the other three modified GCE. Compared Hb-CSDMF/GR/GCE (Fig.2d) with Hb-CS-DMF/GCE (Fig.2a), we can infer that the existence of graphene could greatly enhance the direct electron transfer between $\mathrm{Hb}$ molecules and the underlying electrode. Although Hb-CS/GR/GCE (Fig.2c) also displayed a pair of redox peaks of $\mathrm{Hb}$, these peaks were marked smaller than those of Fig.2d. This phenomenon confirmed that the addition of DMF played an important role in the direct electrode transfer of $\mathrm{Hb}$ in the $\mathrm{Hb}$-chitosan film.

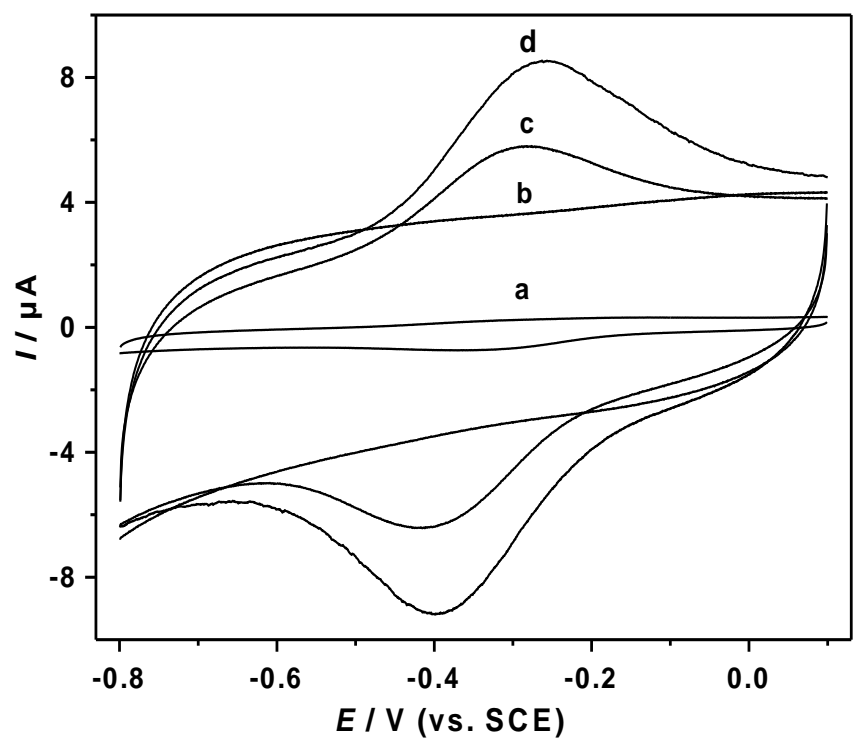

Fig. 2 Cyclic voltammograms of Hb-CS-DMF/GCE (a), CS-DMF/GR/GCE (b), Hb-CS/GR/GCE (c), and
$\mathrm{Hb}-\mathrm{CS}-\mathrm{DMF} / \mathrm{GR} / \mathrm{GCE}$ (d) in 0.1 M PBS (pH 7.0) at scan rate of $0.1 \mathrm{~V} \mathrm{~s}^{-1}$.

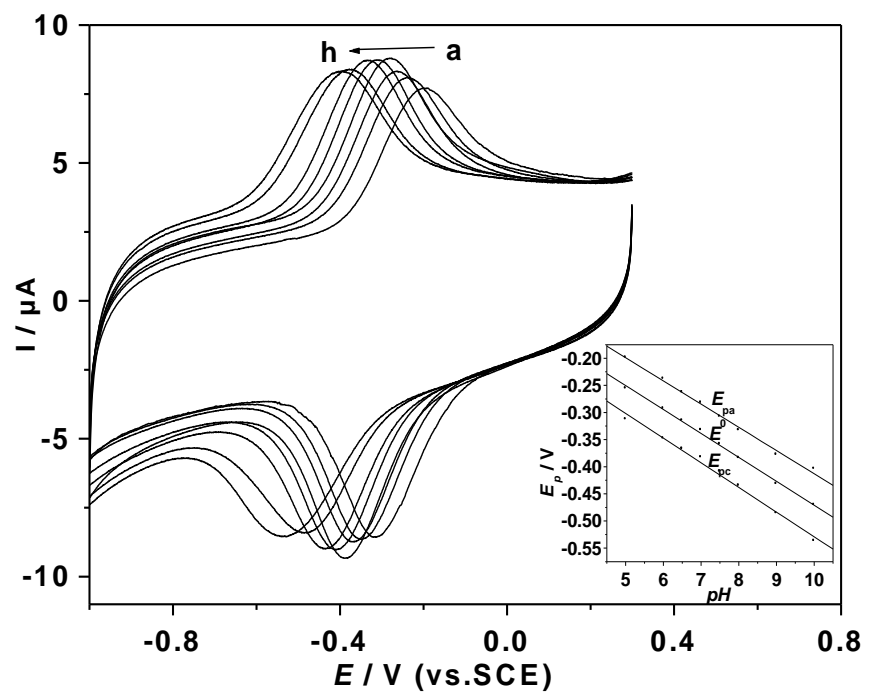

Fig. 3 Cyclic voltammograms of Hb-CS-DMF/GR/ GCE in PBS at different $\mathrm{pH}$ values (curves a h) 5.0, $6.0,6.5,7.0,7.5,8.0,9.0,10.0$. Scan rate: $0.1 \mathrm{~V} \mathrm{~s}^{-1}$. Inset: Plot of $E_{\mathrm{p}}$ vs. pH.

In most cases, the redox behavior of protein is often significantly dependent on the solution pH. Fig.3. shows the CVs of Hb-CSDMF/GR/GCE in PBS at different $\mathrm{pH}$ values. As can be seen, nearly reversible voltammograms with stable and well-defined redox peaks were obtained in the $\mathrm{pH}$ range of 5.0-10.0. The maximum peak current was achieved in PBS 7.0 that consisted with the physiological value. However, both cathodic and anodic peaks shifted negatively with the $\mathrm{pH}$ increasing. All of the $E_{\mathrm{pa}}$, $E_{\mathrm{pc}}$ and $E^{0}$ (formal potential) had a linear relationship with the $\mathrm{pH}$ value (the inset of Fig.3) with the slope value of $-42.8,-45.5$ and -44.1 $\mathrm{mV} \mathrm{pH}^{-1}$, respectively. These slope values were close to the theoretical value of $59.0 \mathrm{mV} \mathrm{pH}^{-1}$ at $25^{\circ} \mathrm{C}$, indicating a reversible, one proton and one electron transfer reaction [29]. The reaction scheme for the electron transfer process of $\mathrm{Hb}$ can be described as reference [30]:

$\mathrm{Hb}$ heme $\mathrm{Fe}(\mathrm{III})+\mathrm{H}^{+}+\mathrm{e}^{-} \rightarrow \mathrm{Hb}$ heme $\mathrm{Fe}(\mathrm{II})$ 


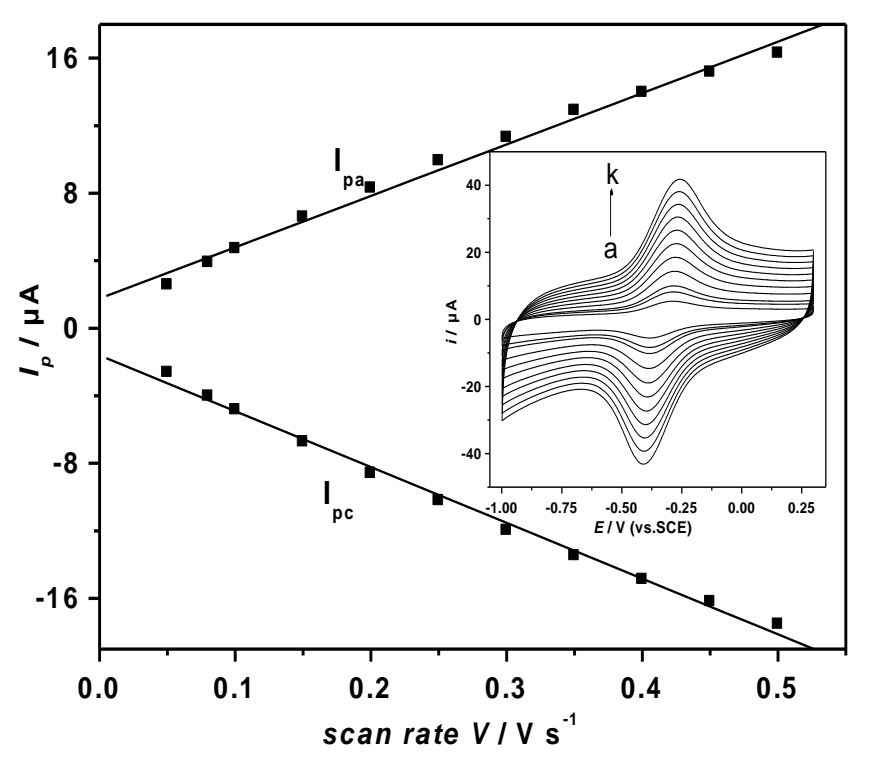

Fig. 4 Plot of peak current vs. scan rate. Inset: Cyclic voltammograms of $\mathrm{Hb}-\mathrm{CS}-\mathrm{DMF} / \mathrm{GR} / \mathrm{GCE}$ in PBS $(\mathrm{pH}$ 7.0) under different scan rates: (curves a k) 0.05, 0.08, $0.1,0.15,0.2,0.25,0.3,0.35,0.4,0.45,0.5 \mathrm{~V} \mathrm{~s}^{-1}$.

The relationship between $\mathrm{CV}$ peak current of $\mathrm{Hb}-\mathrm{CS}-\mathrm{DMF} / \mathrm{GR} / \mathrm{GCE}$ and scan rate was also investigated in Fig.4. As the scan rate increases from $0.05 \mathrm{~V} \mathrm{~s}^{-1}$ to $0.5 \mathrm{~V} \mathrm{~s}^{-1}$, the redox peaks $\left(E_{\mathrm{pa}}\right.$ and $\left.E_{\mathrm{pc}}\right)$ of $\mathrm{Hb}$ shift slightly, resulting in the increase of the peak-to-peak separation $\left(\Delta E_{\mathrm{p}}\right)$. Furthermore, the reduction and oxidation peak currents $\left(I_{\mathrm{pc}}\right.$ and $\left.I_{\mathrm{pa}}\right)$ both increased linearly with the scan rates (Fig.4 inset). All these characteristics suggest that the redox of $\mathrm{Hb}$ on the GR modified electrode is a quasi-reversible surface-controlled electrochemical process.

When $\Delta E_{\mathrm{p}}>200 \mathrm{mV}$, a graph of the $E_{\mathrm{pa}}$ and $E_{\mathrm{pc}}$ versus the logarithm of the scan rates yielded two straight lines with the slopes of $2.3 R T /(1-\alpha) n F$ and $-2.3 R T / \alpha n F$ [31]. From the slopes, transfer coefficient $(\alpha)$ is obtained to be 0.46. According to Laviron's equation [32]:

$$
\begin{gathered}
\log k_{\mathrm{s}}=\alpha \log (1-\alpha)+(1-\alpha) \log \alpha-\log (R T / n F v) \\
\left.-\alpha(1-\alpha) n F \Delta E_{\mathrm{p}} / 2.3 R T\right)
\end{gathered}
$$

Plots of $\Delta E_{\mathrm{p}}$ vs. $\log (R T / n F v)$ produce a straight line. From the slope, the electron transfer rate constant $\left(k_{\mathrm{s}}\right)$ of $\mathrm{Hb}$ at the $\mathrm{Hb}-\mathrm{CS}$ -
DMF/GR/GCE was estimated to be $58.77 \mathrm{~s}^{-1}$, which is larger than that of $\mathrm{Hb}$ immobilized on $\mathrm{Fe}_{3} \mathrm{O}_{4}$-CS film (1.04 $\left.\mathrm{s}^{-1}\right)$ [33], PAM-chitosan hydrogel film $\left(5.51 \mathrm{~s}^{-1}\right)$ [34], SA-MWCNTs $\left(9.54 \pm 0.883 \mathrm{~s}^{-1}\right)$ [35]. These results suggest that GR modified electrode exhibits fast electron transfer.

Moreover, from the integration of the reduction peaks of the $\mathrm{Hb}-\mathrm{CS}-\mathrm{DMF} / \mathrm{GR} / \mathrm{GCE}$ at different scan rates, an average surface coverage of $\mathrm{Hb}$ was calculated to be $1.7 \times 10^{-9} \mathrm{~mol} \mathrm{~cm}{ }^{-2}$. This value was two orders of magnitude higher than the theoretical monolayer coverage of $\mathrm{Hb}$ $\left(1.89 \times 10^{-11} \mathrm{~mol} \mathrm{\textrm {cm } ^ { - 2 }}\right)$ [36] at the bare GCE, which might be mainly because of the following reasons: on one hand, the big surface area of graphene, the three-dimensional structure of CSDMF film and the electrostatic interaction between graphene and $\mathrm{Hb}-\mathrm{CS}-\mathrm{DMF}$ film all benefit the loading of $\mathrm{Hb}$. On the other hand, chitosan remains the activity of $\mathrm{Hb}$. Furthermore, this value is $3.1 \%$ of the total amount of $\mathrm{Hb}$ deposited on the electrode surface, which suggests that only those $\mathrm{Hb}$ in the inner layers of the film close to the electrode and with a suitable orientation can exchange electron with electrode surface.

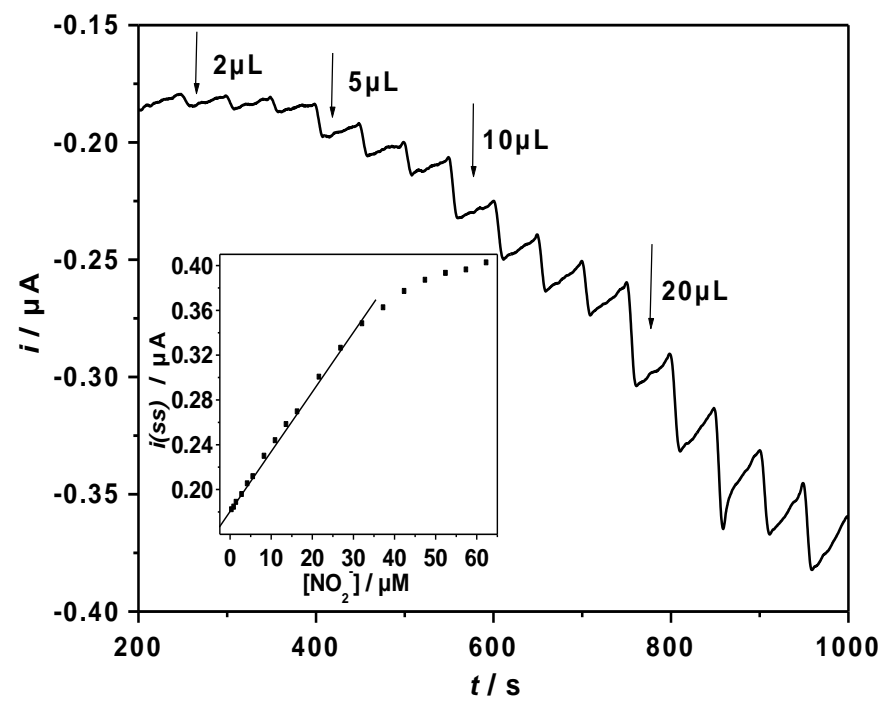

Fig. 5 Amperometric response of Hb-CSDMF/GR/GCE upon successive additions of $1.1 \times 10^{-3}$ $\mathrm{M} \mathrm{NaNO}_{2}$ to $4 \mathrm{~mL}$ of PBS 4.5 at $-0.25 \mathrm{~V}$. Inset: The 
relationship between response current and concentration of $\mathrm{NO}_{2}^{-}$.

\subsection{Electrocatalytic activity of $\mathrm{Hb}$ in $\mathrm{Hb}-\mathrm{CS}$ - DMF/GR film}

The electrocatalytic reduction of $\mathrm{NO}_{2}{ }^{-}$at $\mathrm{Hb}-$ CS-DMF/GR/GCE was studied by amperometry. To improve the performance of the biosensor, the determination condition such as the applied potential and the $\mathrm{pH}$ value of supporting electrolyte was optimized. As the applied potential varied from 0 to $-0.55 \mathrm{~V}$, the maximum response current was achieved at $-0.25 \mathrm{~V}$, so $-0.25 \mathrm{~V}$ was selected as the working potential for the determination of $\mathrm{NO}_{2}^{-}$. The influence of $\mathrm{pH}$ on the response of $\mathrm{Hb}-\mathrm{CS}-\mathrm{DMF} / \mathrm{GR} / \mathrm{GCE}$ was studied between 7.0 and 4.0 in $0.05 \mathrm{M}$ PBS by CV. The peak of the reduction of $\mathrm{NO}_{2}^{-}$can be observed unless the surrounding is acidic. The response current approached maximum when the $\mathrm{pH}$ value of supporting electrolyte was 4.5.

Fig.5. illustrates the amperometric response of the $\mathrm{Hb}-\mathrm{CS}-\mathrm{DMF} / \mathrm{GR} / \mathrm{GCE}$ towards $\mathrm{NO}_{2}{ }^{-}$at applied potential of $-0.25 \mathrm{~V}$ upon successively adding $\mathrm{NO}_{2}{ }^{-}$to a continuous stirring $\mathrm{pH}$ 4.5 PBS. After the addition of an aliquot of $\mathrm{NO}_{2}{ }^{-}$, the reductive peak increased steeply to reach a stable value. The inset of Fig.5 shows the linear relationship of the electrocatalytic reduction peak current and the concentration of $\mathrm{NO}_{2}{ }^{-}$. The linear range is from $5.5 \times 10^{-7}$ to $3.3 \times 10^{-5} \mathrm{M}$ with a correlation coefficient of $0.9989 \quad(n=13)$. The sensitivity is $5.33 \mu \mathrm{A} \mathrm{mM}{ }^{-1}$ and the detection limit is $1.8 \times 10^{-7} \mathrm{M}$ at a signal-to-noise of 3 . The biosensor has lower detection limit than that of other reported papers in the acid medium: (Hb/PCNA $)_{2} / \mathrm{MWNT} / \mathrm{GCE} \quad\left(9.6 \times 10^{-7} \mathrm{M}\right)$ [37], $\mathrm{Hb} / \mathrm{RTILs} / \mathrm{MWNTs} / \mathrm{GCE}\left(8.1 \times 10^{-7} \mathrm{M}\right)$ [38]. The calibration curve showed a level-off tendency when the concentration of $\mathrm{NO}_{2}^{-}$became larger, demonstrating the typical Michaelis-Menten kinetic characteristic of enzyme-based electrode. According to the Lineweaver-Burk equation [39], the apparent Michaelis-Menten constant $\left(K_{\mathrm{m}}\right)$ of $\mathrm{Hb}-\mathrm{CS}-\mathrm{DMF} / \mathrm{GR} / \mathrm{GCE}$ was calculated to be 12 $\mu \mathrm{M}$. This value of $K_{\mathrm{m}}$ for $\mathrm{Hb}$ in this work is smaller than $62 \mathrm{mM}, \mathrm{Hb}$ immobilized on (Hb/PCNA) $)_{2}$ MCNT films [37]. The low value of $K_{\mathrm{m}}$ indicates that $\mathrm{Hb}$ immobilized in $\mathrm{Hb}-\mathrm{CS}$ -
DMF/GR film retains a high biological affinity to nitrite. The reproducibility of the biosensor was investigated in $8.5 \mu \mathrm{M} \mathrm{NO}_{2}^{-}$. Relative standard deviation (RSD) was $2.1 \%$ for with six successive assays at one single modified electrode. The antiinterference ability of the biosensor was also studied. It was found that 200 -fold of $\mathrm{Na}^{+}, \mathrm{K}^{+}, \mathrm{Cl}^{-}$, $\mathrm{NO}_{3}{ }^{-}, \mathrm{CO}_{3}{ }^{2-}$ have almost no influence on the determination of $\mathrm{NO}_{2}{ }^{-}$at $8.5 \mu \mathrm{M}$.

\section{Conclusions}

In conclusion, graphene was used as new material for immobilization of $\mathrm{Hb}$ and was successfully applied in sensing of $\mathrm{NO}_{2}^{-}$. From the SEM images, it is found that the GR nanosheets were lying flat or fold together on the surface of the electrode, and that the Hb-CS-DMF/GR film exhibited a three-dimensional network porous structure. And from the electrochemical analysis, it is proved that the introduction of graphene facilitates the electron transfer between $\mathrm{Hb}$ molecules and the underlying electrode, due to the excellent electrical conductivity of GR and the biocompatibility of chitosan. As a result, the $\mathrm{Hb}$ CS-DMF/GR/GCE showed good sensitivity and stability for the amperometric determination of nitrite. The study shows that graphene holds great promise for electrochemical applications.

\section{Acknowledgements}

This work was financially supported by Natural Science Foundation of Hubei province (2008CDB034) and the Foundation of the Hubei Key Laboratory of Pollutant Analysis \& Reuse Technology (Hubei Normal University, No. KY2010M01).

\section{References}

[1] Novoselov, K.S.; Geim, A.K.; Jiang, S.V.D.; et al. Electric field effect in atomically thin carbon films, Science, 2004, 306, 666-669.

[2] Wu, H.; Wang, J.; Kang, X.H.; et al. Glucose biosensor based on immobilization of glucose oxidase in platinum nanoparticles/graphene/ chitosan nanocomposite film, Talanta, 2009, 
80, 403-406.

[3] Stankovich, S.; Dikin, D.A.; Dommett, G.H.B.; et al. Graphene-based composite materials, Nature, 2006, 442, 282-286.

[4] Wang, Y.; Li, Y.M.; Tang, L.H.; et al. Application of graphene-modified electrode for selective detection of dopamine, Electrochem. Commun., 2009, 11, 889-892.

[5] Li, J.; Guo, S.J.; Zhai, Y.M.; et al. Nafiongraphene nanocomposite film as enhanced sensing platform for ultrasensitive determination of cadmium, Electrochem. Commun., 2009, 11, 1085-1088

[6] Shan, C.S.; Yang, H.F.; Song, J.F.; et al. Direct Electrochemistry of Glucose Oxidase and Biosensing for Glucose Based on Graphene, Anal. Chem., 2009, 81, 2378-2382.

[7] Kang, X.H.; Wang, J.; Wu, H.; et al. Glucose Oxidase-graphene-chitosan modified electrode for direct electrochemistry and glucose sensing, Biosens. Bioelectron., 2009, 25, 901-905.

[8] Wu, J.F.; Xu, M.Q.; Zhao, G.C. Graphenebased modified electrode for the direct electron transfer of Cytochrome $\mathrm{c}$ and biosensing, Electrochem. Commun., 2010, 12, $175-177$.

[9] Xu, H.F.; Dai, H.; Chen, G.N. Direct electrochemistry and electrocatalysis of hemoglobin protein entrapped in graphene and chitosan composite film, Talanta, 2010, 81, 334-338.

[10]Li, J., Guo, S.J., Zhai, Y.M., Wang, E.K. High-sensitivity determination of lead and cadmium based on the Nafion-graphene composite film, Anal. Chim. Acta, 2009, 649, 196-201.

[11]Huang, Y.G.; Ji, J.D.; Hou, Q.N. A study on carcinogenesis of endogenous nitrite and nitrosamine and prevention of cancer, Mutat. Res., 1996, 358, 7-14.

[12] Mirvish, S.S. Role of N-nitroso compounds (NOC) and Nnitrosation in etiology of gastric, esophageal, nasopharyngeal and bladder cancernd contribution to cancer of known exposures to NOC, Cancer. Lett., 1995, 93, 17-48.

[13]Amin, D.; Saleem, K.Y.; Bashir, W.A. Titrimetric determination of chloramine-T and some aldoses by amplification reactions, Talanta, 1982, 29, 694-696.

[14]Ensafi, A.A.; Kazemzadeh, A. Simultaneous determination of nitrite and nitrate in various samples using flow injection with spectrophotometric detection, Anal. Chim. Acta, 1999, 382, 15-21.

[15] Kazemzadeh, A.; Ensafi, A.A. Simultaneous determination of nitrite and nitrate in various samples using flow-injection spectrophotometric detection, Microchem. J, 2001, 69, 61-68.

[16]Ensafi, A.A.; Rezaei, B.; Nouroozi, S. Simultaneous spectrophotometric determination of nitrite and nitrate by flow injection analysis, Anal. Sci., 2004, 20, 1749-1753.

[17] Kazemzadeh, A.; Ensafi, A.A. Sequential flow injection spectrophotometric determination of nitrite and nitrate in various samples, Anal. Chim. Acta, 2001, 442, 319326.

[18]Brons, C.; Olieman, C. Study of the highperformance liquid chromatographic separation of reducing sugars, applied to the determination of lactose in milk, $J$. Chromatogr., 1983, 259, 79-86.

[19]Beebe, J.M.; Gilpin, R.K. Determination of $\alpha-$ and $\beta$-lactose in dairy products by totally aqueous liquid chromatography, Anal. Chim. Acta, 1983, 146, 255-259.

[20]Zazoua, A.; Hnaien, M.; Cosnier, S.; et al. A new RP/catalase biosensor based on microconductometric transduction for nitrite determination, Mater. Sci. Eng. C, 2009, 29, 1919-1922.

[21]Ko, W.Y.; Chen, W.H.; Cheng, C.Y.; et al. Highly electrocatalytic reduction of nitrite ions on a copper nanoparticles thin film, Sensor. Actuat. B-Chem., 2009, 137, 437-441.

[22]Zheng, D.; Hu, C.; Peng, Y.; et al. Acarbon nanotube/polyvanillin composite film as an electrocatalyst for the electrochemical oxidation of nitrite and its application as a nitrite sensor, Electrochim. Acta, 2009, 54, 4910-4915.

[23] Yang, Sh.L.; Zeng, X.D.; Liu, X.Y.; et al. Electrocatalytic reduction and sensitive determination of nitrite at nano-copper coated multi-walled carbon nanotubes modified 
glassy carbon electrode, J. Electroanal. Chem., 2010, 639, 181-186.

[24]Liu, K.P. ; Zhang, J.J. ; Yang, G.H. ; et al. Direct electrochemistry and electrocatalysis of hemoglobin based on poly(diallyldimethylammonium chloride) functionalized graphene sheets/room temperature ionic liquid composite film, Electrochem. Commun., 2010,12,402-405.

[25]Sorlier, P.; Denuzière, A.; Viton, C.; et al. Relation between the Degree of Acetylation and the Electrostatic Properties of Chitin and Chitosan, Biomacromolecules, 2001, 2, 765772.

[26]Hummers, W.; Offeman, R.; Preparation of graphitic oxide. J. Am. Chem. Soc., 1958, 80: 1339.

[27]Xiong, H.Y.; Chen, T.; Zhang, X.H.; et al. Electrochemical property and analysis application of biosensors in miscible nonaqueous media-room-temperature ionic liquid, Electrochem. Commun., 2007, 9, 1648-1654.

[28]Zhang, Z.; Chouchane, S.; Magliozzo, R.S.; et al. Direct Voltammetry and Catalysis with Mycobacterium tuberculosis CatalasePeroxidase, Peroxidases, and Catalase in Lipid Films, Anal. Chem., 2002, 74, 163-170.

[29]Bard, A.J.; Faulkner, L.R.; Electrochemical methods: fundamentals and applications, 2nd edn. Wiley, New York, 2001, pp236.

[30]Han, X.J.; Huang, W.M.; Jia, J.B.; et al. Direct electrochemistry of hemoglobin in egg/phosphatidylcholine films and its catalysis to $\mathrm{H}_{2} \mathrm{O}_{2}$, Biosens. Bioelectron., 2002, $17,741-746$.

[31]Zhao, X.J.; Mai, Z.B.; Kang, X.H.; et al. Clay-chitosan-gold nanoparticle nanohybrid: Preparation and application for assembly and direct electrochemistry of myoglobin, Electrochim. Acta, 2008, 53, 4732-4739.

[32]Laviron, E.; General expression of the linear potential sweep voltammogram in the case of diffusionless electrochemical systems, $J$. Electronanal. Chem., 1979, 101, 19-28.

[33]Zheng, N.; Zhou, X.; Yang, W.Y.; et al. Direct electrochemistry and electrocatalysis of hemoglobin immobilized in a magnetic nanoparticles-chitosan film, Talanta, 2009, 79, 780-786.

[34]Zeng, X.D.; W, W.Zh.; Li, X.F.; et al. Direct electrochemistry and electrocatalysis of hemoglobin entrapped in semiinterpenetrating polymer network hydrogel based on polyacrylamide and chitosan, Bioelectrochemistry, 2007, 71, 135-141.

[35]Zhao, H.Y.; Zheng, W.; Meng, Z.X.; et al. Bioelectrochemistry of hemoglobin immobilized on a sodium alginate-multiwall carbon nanotubes composite film, Biosens. Bioelectron., 24 (2009) 2352-2357.

[36] Wang, S.F.; Chen, T.; Zhang, Z.L.; et al. Direct Electrochemistry and Electrocatalysis of Heme Proteins Entrapped in Agarose Hydrogel Films in Room-Temperature Ionic Liquids, Langmuir, 2005, 21, 9260-9266.

[37]Zhang, L.Y.; Yi, M. Electrochemical nitrite biosensor based on the immobilization of hemoglobin on an electrode modified by multiwall carbon nanotubes and positively charged gold nanoparticle, Bioprocess. Biosyst. Eng., 2009, 32, 485-492.

[38] Wei, W.; Jin, H.H.; Zhao, G.Ch. A reagentless nitrite biosensor based on direct transfer of hemoglobin on a room temperature ionic liquid/carbon nanotube-modified electrode, Microchim. Acta, 2009, 164, 167-171.

[39] Kamin, R.A. Wilson, G.S. Rotating ring-disk enzyme electrode for biocatalysis kinetic studies and characterization of the immobilized enzyme layer, Anal. Chem., 1980, 52, 1198-1205. 